\title{
A comparison of wedge and segmental resection of the lung
}

\author{
MYRON J. JACOBSON ${ }^{1}$, LLOYD ZAND, \\ ROBERT T. FOX, and WILLIAM LEES \\ Departments of Surgery and Municipal Tuberculosis Sanitarium, Chicago; The University \\ of Chicago, Pritzker School of Medicine; Northwestern University Medical School; and \\ Loyola University, Stritch School of Medicine
}

\begin{abstract}
Jacobson, M. J., Zand, L., Fox, R. T., and Lees, W. (1976). Thorax, 31, 365-368. A comparison of wedge and segmental resection of the lung. In the past few years there has been increasing use of limited resection for pulmonary carcinoma, especially in patients with restricted cardiorespiratory function. Because there is frequently a choice as to the type of limited resection, it was considered worth while to review the safety and efficiency of the two principal types. In total, 212 wedge resections and 281 segmental resections are reported. Despite certain theoretical advantages to segmentectomy, wedge resection carried a lower complication rate. Seventy-one per cent of wedge resections were free of complications compared to $54 \%$ of segmental resections. Minor complications were defined as apical air space and apical haematoma. The incidence of minor complications was similar for each group, $22 \%$ for wedge resections and $27 \%$ for segmentectomies. However, there was a significantly higher major complication rate in the segmental resection group (19\%) compared to the wedge group $(7 \%)$. This is understandable, considering the amount of raw lung surface exposed after segmental resection. It appears that where it is surgically feasible, wedge resection should be practised.
\end{abstract}

For primary lung carcinoma, the most widely practised operations have been lobectomy, where feasible, or pneumonectomy. More recently, there has been renewed interest in the role of limited resection in pulmonary carcinoma. Shields and Higgins (1974) studied a group of patients with carcinoma in whom local resection was performed as a compromise procedure. They included patients with markedly reduced lung function, severe heart disease, or a previous contralateral resection. Their series included 40 such patients from a group of over 3000 patients operated on in US Veterans Administration Hospitals. The fiveyear survival was $28.5 \%$. The authors noted that 'The merits of selecting a segmental rather than a wedge resection are at present unanswerable'.

In another small series of 17 patients with bronchial carcinoma managed by segmental resection, le Roux (1972) achieved a $29 \%$ survival rate. Bonfils-Roberts and Clagett (1972) also noted

1Present address: Department of Surgery, State University of New York at Stony Brook, Stony Brook, New York, USA, 11794 a similar survival rate, as did Steele et al. (1966). These authors considered segmental resection a reasonable and justifiable procedure in carefully selected patients with lung malignancy.

Jensik and colleagues (1973) reported a $56 \%$ five-year survival in 69 similar patients. The different results from those in the other series are probably due to patient selection.

For metastatic malignancy local resection has achieved a well-established role (Clagett and Woolner, 1964; Marks, 1974).

Because of the broadened applications of limited pulmonary resection, we considered it worth while to review the safety and effectiveness of the two principal types.

Advocates of segmentectomy cite several reasons for the superiority of this method: (1) it is an anatomical dissection with individual ligation of hilar structures; (2) it does not transgress intersegmental planes; (3) there is no mass crushing and suturing of lung parenchyma; (4) any small adjacent areas of bleeding or air leak can be individually ligated. 
In favour of wedge resection of pulmonary tissue are the ease and rapidity with which it can be accomplished and the fact that the lung edge and overlying visceral pleura are reapproximated, leaving essentially no area of raw lung surface.

Linden and Saikku (1966) reported two empyemas, 13 residual intrathoracic air spaces, and two fatalities in their series of 34 segmentectomies. A $39.6 \%$ complication rate was noted by Langston, Barker, and Pyle (1966) after segmental resection. This covered major and minor complications but only $7.2 \%$ of the total were major. Data for wedge resection were not separately noted.

In their analysis of postoperative pulmonary haemorrhage, Langer et al. (1966) found no significant differences in the incidence of a haemorrhage after wedge resection performed with a mechanical apparatus $(3.2 \%)$, segmentectomy $(3.7 \%)$, and lobectomy $(3.8 \%)$. They did note a significant correlation between postoperative bleeding and empyema. These authors concluded that when haemorrhage was treated conservatively, there was much greater difficulty with reexpansion of the lung than when rethoracotomy was performed.

Gale, Coulthard, and Delarue (1962) had a $7 \cdot 1 \%$ rate of major complications after segmental resections in patients (13 of 182) who had been adequately treated medically. There were none in 46 wedge resections.

\section{CLINICAL MATERIAL}

Although the cases analysed were treated in a large municipal tuberculosis hospital, the principles elucidated have general applicability.

The data for all segmental and wedge resections performed at the Municipal Tuberculosis Sanitarium of Chicago for an eight-year period (195562) were reviewed. If a combined operation was done on the same side, such as segmentectomy combined with lobectomy, the case was excluded from the series. Surgery to remove residual disease was performed after a minimum of six months of medical therapy.

In all, 281 segmental resections and 212 wedge resections are reported. In this series, the amount of pulmonary tissue to be removed did not necessarily influence the decision as to the type of operation. Wedge resection was usually favoured whenever it was feasible to do so, that is, when an adequate margin between the palpable disease and the hilar structures was present. Virtually all of the operations were performed by the resident staff under the supervision of the two senior $\stackrel{\overrightarrow{\bar{s}}}{\vec{*}}$ surgeons.

In no instance was a mechanical suturing device $\overline{0}$ used. Lees' wedge clamps ${ }^{1}$ were used in almost $\frac{\bar{c}}{\circ}$ all cases, and closure was accomplished with two $\propto$ rows of continuous sutures-either catgut or silk. Usually a mattress suture of silk was placed at the apex of the wedge.

\section{RESULTS}

In tabulating the results, complications were $\underset{x}{\vec{*}}$ classified as major or minor. Minor complications $\stackrel{\omega}{-}$ were arbitrarily defined as either apical haema- $\rightarrow$ toma or apical air space which required no treat- ${ }^{\omega}$ ment. Late follow-up radiographs obtained six months after surgery disclosed no evidence of ${ }^{-}$ residual haematoma or localized pneumothorax. A few patients, however, were lost to follow-up.

Seventy-one per cent of wedge resections were free of complications compared to $54 \%$ of seg-mental resections $(\mathbf{P}<0.001)$. There was no signi- 0 ficant difference in minor complications between the two groups. Twenty-two per cent of patients who underwent wedge resection had minor complications compared to $27 \%$ of those undergoingo segmentectomy. Thus, in the wedge group, $93 \%$ had either no complications or minor complica $\mathbb{D}$ tions. The comparable figure for the segmen $\overrightarrow{\overrightarrow{0}}$ tectomy group is $81 \%$. These data are summarized 3 in Tables I and II.

T A B L E I

INCIDENCE OF COMPLICATIONS

\begin{tabular}{|c|c|c|c|c|c|}
\hline & \multicolumn{2}{|c|}{$\begin{array}{l}\text { Wedge } \\
\text { Resection }\end{array}$} & \multicolumn{2}{|c|}{$\begin{array}{l}\text { Segmental } \\
\text { Resection }\end{array}$} & \\
\hline & No. & $\%$ & No. & $\%$ & \\
\hline $\begin{array}{l}\text { Uncomplicated } \\
\text { Complicated } \\
\text { Minor } \\
\text { Major } \\
\text { Died }\end{array}$ & $\begin{array}{r}150 \\
62 \\
47 \\
14 \\
1\end{array}$ & $\begin{array}{c}71 \\
29 \\
22 \\
7 \\
0.5\end{array}$ & $\begin{array}{r}150 \\
131 \\
76 \\
54 \\
1\end{array}$ & $\begin{array}{l}54 \\
46 \\
27 \\
19 \\
0.4\end{array}$ & $\begin{array}{l}P<0.001 \\
P<0.001 \\
P>0.1 \\
P<0.001\end{array}$ \\
\hline Total & 212 & & 281 & & \\
\hline
\end{tabular}

T A B L E I I MINOR COMPLICATIONS

\begin{tabular}{l|c|c|c|c|}
\hline \multirow{2}{*}{ Complication } & \multicolumn{2}{c|}{$\begin{array}{c}\text { Wedge } \\
\text { Resection (212) }\end{array}$} & \multicolumn{2}{c}{$\begin{array}{c}\text { Segmental } \\
\text { Resection (280) }\end{array}$} \\
\cline { 2 - 6 } & No. & $\%$ & No. & $\%$ \\
\hline $\begin{array}{l}\text { Apical haematoma } \\
\text { Apical air space }\end{array}$ & 26 & 12 & 26 & 18 \\
\hline
\end{tabular}
Available from the Pilling Company, Philadelphia, Pa, USA
Catalog nos 34-2800 and 34-2802. 
Major complications are tabulated in Tables III and IV. The segmental group sustained a $20 \%$ incidence of major complications compared to $7 \%$ in the wedge group. One patient in each group died in the immediate postoperative period. Each of these patients had severe postoperative intrapleural haemorrhage necessitating multiple transfusions. Each died on the third day after operation, one of cardiac failure and the other with fulminating Pseudomonas pneumonia.

T A B L E I I I

MAJOR COMPLICATIONS

\begin{tabular}{l|c|cc}
\hline & & \multicolumn{2}{|c}{ Major Complications } \\
\cline { 3 - 4 } & Number & No. & $\%$ \\
\hline Wedge resection & 212 & 14 & 7 \\
Segmental resection & 280 & 55 & 20 \\
Total & 492 & 69 & 14 \\
\hline
\end{tabular}

$\mathrm{P}<0.001$.

T A B L E I V

TYPE OF MAJOR COMPLICATION

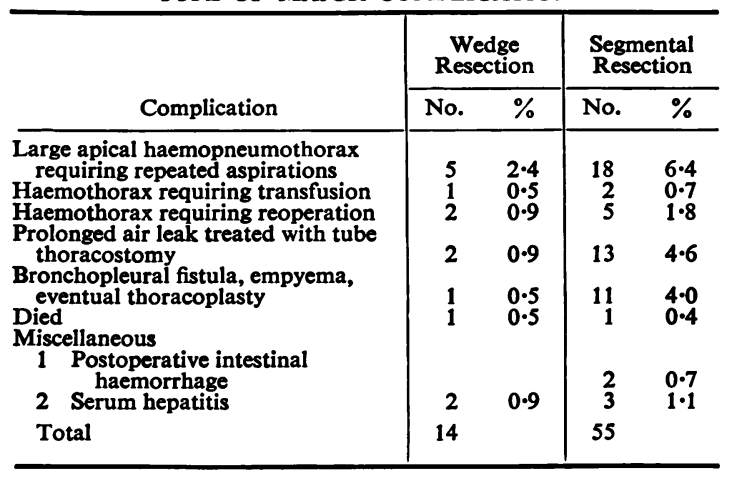

For the purpose of this study, major postoperative haemorrhage was defined as continued intrapleural bleeding in which more than three units of blood was required after the patient had left the operating room. Eight patients $(3.8 \%)$ in the wedge group had significant postoperative bleeding, and two of these $(0.9 \%)$ required reexploration of the thoracic cavity. In contrast, 25 $(8.9 \%)$ patients after segmentectomy had bleeding and five $(1.8 \%)$ of this group required emergency reoperation.

Prolonged air leak occurred in $13(4.6 \%)$ patients who underwent segmental resection. This complication occurred in only two $(0.9 \%)$ of the wedge group.
The other serious group of postoperative problems involved bronchopleural fistula and empyema. Only one patient $(0.5 \%)$ of the wedge group but $11(4.0 \%)$ patients of the segmental group developed this complication.

All 12 patients with postoperative bronchopleural fistula and empyema required eventual thoracoplasty to obliterate the space.

\section{DISCUSSION}

Critics of wedge resection cite several theoretical objections to the operation. (1) A wedge resection does not respect the intrapulmonary anatomy, in that portions of one or more segments may be resected without attention to the bronchovascular anatomy; (2) there is a higher morbidity rate because vessels and bronchioles are not individually ligated but are controlled with a running suture; (3) there is more distortion of the pulmonary anatomy as the lung edges and visceral pleura are approximated. These objections, however, seem more theoretical than real. (In some centres it has even become unfashionable to use the term wedge resection, and, when such a resection is performed, the term subsegmental resection is often substituted.)

Conversely, segmental resection, no matter how carefully it is performed, leaves a raw area of lung surface. Despite careful ligation of all visible fine blood vessels and bronchioles, there is still a tendency for this raw surface to leak both air and blood. This is the source of the increased complications in most patients.

\section{REFERENCES}

Bonfils-Roberts, E. A. and Clagett, O. T. (1972). Contemporary indications for pulmonary segmental resections. Journal of Thoracic and Cardiovascular Surgery, 63, 433.

Boyden, E. A. (1945). The intrahilar and related segmental anatomy of the lung. Surgery, 18, 706.

Chamberlain, J. M. (1957). Segmental resection for pulmonary tuberculosis. In The Surgical Management of Pulmonary Tuberculosis, edited by J. D. Steele, p. 52. Thomas, Springfield, Illinois.

Churchill, E. D. and Belsey, R. (1939). Segmental pneumonectomy in bronchiectasis. Annals of Surgery, 109, 481.

Clagett, O. T. and Woolner, L. B. (1964). Surgical treatment of solitary metastatic pulmonary lesion. Medical Clinics of North America, 48, 939.

Gale, G. L., Coulthard, H. S., and Delarue, N. C. (1962). Resection in pulmonary tuberculosis, with a special study on the influence of residual disease upon relapse. Journal of Thoracic and Cardiovascular Surgery, 43, 239. 
Jensik, R. J., Faber L. P., Milloy, F. J., and Monson, D. O. (1973). Segmental resection for lung cancer. Journal of Thoracic and Cardiovascular Surgery, 66, 563.

Langer, J., Czyzewski, K., Mieszkowski, J., and Palka, W. (1966). Postoperative hemorrhage after pulmonary resection. Diseases of Chest, 50, 27.

Langston, H. T., Barker, W. L., and Pyle, M. M. (1966). Surgery in pulmonary tuberculosis: 11year review of indications and results. Annals of Surgery, 164, 567.

le Roux, B. T. (1972). Management of bronchial carcinoma by segmental resection. Thorax, 27, 70 .

Linden, L. W. F. and Saikku, L. A. (1966). Resection therapy in pulmonary tuberculosis-early results and complications. Acta Chirurgica Scandinavica, 127, 619.
Marks, P. (1974). Multiple thoracotomy for metastatic pulmonary neoplasm. Thorax, 29, 248.

Shields, T. W. and Higgins, G. A. Jr. (1974). Minimalo pulmonary resection in treatment of carcinoma of $\overline{\bar{c}}$ the lung. Archives of Surgery, 108, 420.

Steele, J. D., Kleitsch, W. P., Dunn, J. E. Jr., and ${ }^{\varrho}$ Buell, P. P. (1966). Survival in males with bron-s chogenic carcinomas resected as asymptomaticsolitary pulmonary nodules. Annals of Thoracic. Surgery, 2, 368.

Requests for reprints to: Professor M. J. Jacobson, Department of Surgery, State University of New York at Stony Brook, Stony Brook, New York, USA, , 11794. 